\title{
A rare morphological variation of the coeliac trunk in a Sri Lankan cadaver
}

\begin{abstract}
The classic branches of the coeliac trunk are the left gastric, common hepatic and the splenic arteries. In a routine dissection of a 72year old male cadaver at the Faculty of Medicine, University of Kelaniya, Sri Lanka a variation of five branches originating directly from the abdominal aorta at the level of the origin of coeliac trunk was observed; left gastric artery, splenic artery, main hepatic artery, first direct hepatic branch and second direct hepatic branch. This deviation from three main classic branches of coeliac trunk to five direct branches is a very rare occurrence. Records of this type of vascular patterns are really important in planning and performing abdominal surgical and radiological procedures as well as radiological interventions.
\end{abstract}

Keywords: coeliac trunk, rare, variation, cadaver, Sri Lanka
Volume 13 Issue 5 - 2020

\author{
Lanka Ranaweera,' Kasun Withana, ${ }^{2}$ Suneth \\ Weerasingha ${ }^{3}$ \\ 'Department of Anatomy, Faculty of Medicine, University of \\ Kelaniya, Sri Lanka \\ ${ }^{2}$ Colombo East Base Hospital, Mulleriyawa, Sri Lanka \\ ${ }^{3}$ Teaching Hospital, Peradeniya, Sri Lanka
}

Correspondence: Lanka Ranaweera, Department of Anatomy, Faculty of Medicine, University of Kelaniya, I I0 I0, Sri Lanka, Tel +9477758532I, Email lana@kln.ac.lk

Received: August 25, 2020 | Published: October 22, 2020

\section{Introduction}

The coeliac trunk is the first anterior branch of the abdominal aorta which arises immediately below the aortic opening of the diaphragm at the level of the intervertebral disc between the twelfth thoracic and first lumbar vertebrae. The left gastric artery, common hepatic artery and splenic artery are the classical three branches of the coeliac trunk in almost $80 \%$ of the cases. ${ }^{1}$ The Common hepatic artery once branched out, forms the coeliac trunk gives of the right gastric and gastroduodenal arteries, and continues as the proper hepatic artery to supply the liver. The gastroduodenal artery divides into the pancreaticoduodenal artery and right gastro-epiploic artery supplying the stomach, head of the pancreas, duodeno-jejunal flexure and the common bile duct. The splenic artery is a separate vessel form the coeliac trunk that courses along the superior border of the pancreas and supplies the spleen, fundus of the stomach, body and tail of pancreas and greater omentum. The said description of the coeliac trunk, its branches and their supplying organs reflects the embryological origin and development of the foregut. Wide variations of the origin, number of branches and their distribution occur in the coeliac trunk system indicates the importance of the field of surgery and radiology. ${ }^{1,2}$ The normal origin of the coeliac trunk is at the level of the twelfth thoracic vertebrae in the retro peritoneum. The length and the diameter of the coeliac trunk are also subjected to wide variations which are surgically relevant. ${ }^{3,4}$ Where normal anatomy was present, the mean length of the celiac trunk was $1.9+0.08 \mathrm{~cm}$ and its mean arterial diameter was $0.78+0.08 \mathrm{~cm} .{ }^{4}$ Single coeliac trunk is the commonest type but multiple separate origins of the aforementioned main branches are seen. It is less common to find all the three branches originating separately with accessory arteries branching out from the anterior surface of the abdominal aorta. ${ }^{5,6}$ Therefore the variation of the coeliac trunk described here has a high value in improving the anatomical knowledge of vascular variations in this surgically important region.

\section{Case report}

The case report that is described here is of a 72year old male who died of myocardial infarction with a history of ischemic heart disease but without a known vascular anomaly by clinical details. The body was donated for routine teaching and learning activities of the
Department of Anatomy, Faculty of Medicine, University of Kelaniya, Sri Lanka. Written consent had been granted when the cadaver wad donated by the relatives. The dissection carried out according to the guidelines stated in the Cunningham Manual of Practical anatomy. ${ }^{7}$ The abdominal cavity was opened into and the retroperitoneum was reached, preserving the vascular pedicles and the supplying organs by the coeliac trunk tracing proximally and distally in relation to the well-known anatomical landmarks of the abdominal cavity. The identified arteries in the vicinity of the coeliac trunk were labeled and photographed using a digital camera. Tracing of the vessels were done up to the supplying organ or part of the organ to confirm the distribution. In this case, instead of the coeliac trunk we observed five arterial branches originating directly from the abdominal aorta (Figure 1); left gastric artery (Branch A), splenic artery (Branch B), main hepatic artery (Branch $\mathrm{C})$, first direct hepatic branch $(\mathrm{H} 1)$ and second direct hepatic branch $(\mathrm{H} 2)$.

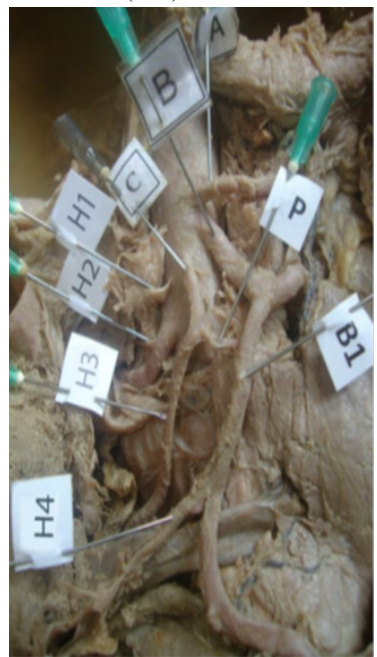

Figure I The five arterial branches from abdominal aorta related to the coeliac trunk; A-left gastric artery, B- splenic artery, C- main hepatic artery, $\mathrm{HI}$ - first direct hepatic branch, $\mathrm{H} 2$ - second direct hepatic branch, $\mathrm{H} 3$ - hepatic branch of main hepatic artery and $\mathrm{H} 4$ - hepatic branch of a descending branch of splenic artery, BI- descending branch of splenic artery which is divided into $\mathrm{H} 4$ branch and pancreaticoduodenal branch, $\mathrm{P}$ - pancreatic branch of main hepatic artery. 
The uppermost branch or left gastric artery (Branch A) originated at the lower border of the twelfth thoracic vertebra whereas the lowest branch (Branch H2) corresponded to the upper border of the first lumbar vertebra. The other branches originated in an oblique line somewhat towards the right side. The branch A was the main supplier to the stomach lesser curvature corresponding to the left gastric artery. The branch $\mathrm{B}$, being the largest, was seen bifurcating $2.3 \mathrm{~cm}$ distal to the origin from the aorta forming a curved branch ascending towards the lesser curvature of the stomach, and a descending branch coursing towards the head of the pancreas and the duodenum. This ascending branch represents the continuation of the splenic artery. The descending branch (B1) bifurcates $4.1 \mathrm{~cm}$ distal to its origin giving a hepatic branch (H4) and a pancreatico-duodenal branch supplying the pancreatic head mainly its inferior aspect and the anterior part of the uncinate process running in the groove formed by the 2 nd and 3rd part of the duodenum. Interestingly, there were 4 identifiable arterial branches (H1, H2, H3 and H4) to the liver (Figure 1). The $\mathrm{H} 1$ branch was the first direct hepatic branch and it originates from aorta just below and right to the main hepatic artery. The $\mathrm{H} 2$ branch was the second direct hepatic branch and it arises from aorta below to $\mathrm{H} 1$ branch. The $\mathrm{H} 3$ was a hepatic branch of main hepatic artery and $\mathrm{H} 4$ was a branch of a descending branch of splenic artery (B1). All the hepatic branches except $\mathrm{H} 2$ showed similar small caliber. The $\mathrm{H} 2$ branch shows somewhat larger diameter which is only smaller to splenic artery. Importantly, all the branches of H1 to H4 showed an unbranching course until they reached the liver parenchyma. Moreover, the pancreas was supplied by a pancreatic branch $(\mathrm{P})$ from the main hepatic artery and the pancreaticoduodenal branch of descending branch of splenic artery (B1). None of the aforementioned branches demonstrated connecting branches with each other. Both portal venous system and the hepatic veins demonstrated normal general arrangement. The extra-hepatic biliary tree showed no significant variations to the general pattern. Further, none of the visceral organs supplied by this variation showed macroscopic anomalies or deviation from the general architecture.

\section{Discussion}

The coeliac trunk arises in the anterior aspect of the aorta, just after it passes the diaphragmatic aortic hiatus, at the level of the $12^{\text {th }}$ thoracic and first lumbar vertebrae and trifurcates into the common hepatic artery, left gastric artery and splenic artery. However, according to literature there are lot of variations of origin of the coeliac trunk and its main branches. Unlike the vascular abnormalities in the limbs, the variation in coeliac trunk certainly needs attention because of their surgical importance in the abdominal region. ${ }^{8}$ These variations are due to the developmental abnormalities in the ventral splanchnic arteries. The prevalence of classic coeliac trunk trifurcation is between $40 \%$ and $94.2 \%$ in cadaveric studies whereas radiological studies reported up to $95.9 \%$ and liver transplantation studies indicated $98.3 \%{ }^{9-12}$ The prevalence of bifurcation of the celiac trunk is around 7.1\%. ${ }^{13,14}$ The most frequent type of bifurcation (3\%) is the hepatosplenic trunk, with the left gastric artery originating from the abdominal aorta. ${ }^{15-17}$ Additional branches or collaterals of the celiac trunk have been reported from several studies all over the world. ${ }^{18-20}$ Interesting, the most infrequent variation of the abdominal vasculature is the absence of the celiac trunk indicating the mean prevalence of $0.38 \% .^{13,14,21}$ Adding to this list our study reports the very first rare case of absence of celiac trunk in Sri Lankan context. In this case, the left gastric artery, splenic artery and main hepatic artery arise independently from the aorta with another two additional direct tributaries to the liver. There have been no such cases reported previously in the country.
Importantly, Sri Lankan studies on celiac trunk gross anatomical variations are scarce and .confined to three studies. Out of that two reports claimed rare variation of celiac trunk; coeliomesenteric trunk and hepatosplenomesenteric trunk. ${ }^{22,23}$ The other one is a preliminary cadaveric study of branching pattern of the coeliac trunk in a selected Sri Lankan population and reported $72.7 \%$ of classic coeliac trunk division of normal 3 main branches while $27.3 \%$ had additional left and right inferior phrenic arteries as the first branches. ${ }^{24}$ Therefore, awareness of anatomical variations of the celiac trunk is important to plan abdominal surgeries or image guided interventional procedures especially in liver transplantation and laparoscopic surgery to avoid patient complications. Hence, more cadaveric studies on celiac trunk are needed to develop the Sri Lankan data base and it should be updated from time to time.

\section{Conclusions}

We have observed five direct branches, left gastric artery, splenic artery, main hepatic artery, first direct hepatic branch and second direct hepatic branch, originating directly from the abdominal aorta at the level of the origin of coeliac trunk. The precise description of the vasculature of coeliac trunk is warranted due to uncommon variations encountered during complex abdominal surgeries.

\section{Acknowledgments}

We dedicate this article to the memory of people who donated their bodies to the Department of Anatomy, Faculty of Medicine, University of Kelaniya, Sri Lanka, through body donation program.

\section{Conflicts of interest}

Authors declare that there are no conflicts of interest.

\section{Funding}

None.

\section{References}

1. Prakash, Rajini T, Mokhasi V, et al. Coeliac trunk and its branches: anatomical variations and clinical implications. Singapore Med J. 2012;53(5):329-331.

2. Murakami T, Mabuchi M, Giuvarasteanu I, et al. Coexistence of rare arteries in the human celiaco-mesenteric system. Acta Med Okayama. 1998;52(5):239-244.

3. Gorantla, VR, Nayak BS, Potu BK. Variations of the celiactrunk and its branches associated with the shift of vascular hilum (portahepatis) of the liver. Bratisl Lek Listy. 2012;113(2):120-122.

4. Malnar D, Klasan GS, Miletić D, et al. Properties of the celiactrunkanatomical study. Coll Antropol. 2010;34(3):917-921.

5. Yamaki K, Tanaka N, Matsushima T, et al. A rare case of absence of the celiac trunk: the left gastric, the splenic, the common hepatic and the superior mesenteric arteries arising independently from the abdominal aorta. Ann Anat. 1995;177(1):97-100.

6. Nayak SR, Prabhu LV, Krishnamurthy A, et al. Additional branches of celiac trunk and its clinical significance. Rom J Morphol Embryol. 2008;49(2):247-249.

7. Romanes GJ. Cunningham's Manual of Practical Anatomy. Thorax and abdomen, 15th edn. India: Oxford University Press; 1986.

8. Cicekcibasi AE, Uysal I, Seker M, et al. A rare variation of the coeliac trunk. Ann Anat. 2005;187(4):387-391. 
9. Chitra R. Clinically relevant variations of the coeliac trunk. Singapore Med Journal. 2005;51(3):216-219.

10. Katsume K, Kanamura E, Sakai K, et al. Statistics report concerning variations in abdominal visceral arterial supply. Kurume Igaku Zasshi. 1978;41:266-273.

11. Koops A, Wojciechowski B, Broering DC, et al. Anatomic variations of the hepatic arteries in 604 selective celiac and superior mesenteric angiographies. Surg Radiol Anat. 2004;26(3):239-244.

12. Hiatt JR, Gabbay J, Busuttil RW. Surgical anatomy of the hepatic arteries in 1000 cases. Ann Surg. 1994;220(1):50-52.

13. Panagouli E, Venieratos D, Lolis E, et al. Variations in the anatomy of the celiac trunk: A systematic review and clinical implications. Ann Anat. 2013;195(6):501-511.

14. Pinal-Garcia DF, Nuno-Guzman CM, Gonzalez-Gonzalez ME, et al. The Celiac Trunk and Its Anatomical Variations: A Cadaveric Study. J Clin Med Res 2018;10(4):321-329.

15. Song SY, Chung JW, Yin YH, et al. Celiac axis and common hepatic artery variations in 5002 patients: systematic analysis with spiral CT and DSA. Radiology. 2010;255(1):278-288.

16. Mburu KS, Alexander OJ, Hassan S, et al. Variations in the branching pattern of the celiac trunk in a Kenyan population. Int $J$ Morphol. 2010;28(1):199-204.
17. Chen H, Yano R, Emura S, et al. Anatomic variation of the celiac trunk with special reference to hepatic artery patterns. Ann Anat. 2009;191(4):399407.

18. Vandamme JP, Bonte J. The branches of the celiac trunk. Acta Anat. 1985;122(2):110-114.

19. Loukas M, Hullett J, Wagner T. Clinical anatomy of the inferior phrenic artery. Clin Anat. 2005;18(5):357-365.

20. Greig HW, Anson BJ, Coleman SS. The inferior phrenic artery; types of origin in 850 body-halves and diaphragmatic relationship. $Q$ Bull Northwest Univ Med Sch. 1951;25(4):345-350.

21. Venieratos D, Panagouli E, Lolis E, et al. A morphometric study of the celiac trunk and review of the literature. Clin Anat. 2013;26(6):741-750.

22. Arudchelvam J. Coeliomesenteric trunk - a rare variation to be aware of. The Sri Lanka Journal of Surgery. 2019;37(3):8-9.

23. Samarawickrama MB. Hepatosplenomesenteric trunk; a rare variation of the celiac trunk. Galle Medical Journal. 2010;15(1):39-41.

24. Edirisinghe EAST, De Fonseka HFDG, Dissanayake MHP, et al. Preliminary cadaveric study of branching pattern of the coeliac trunk in a selected Sri lankan population. Proceedings of International Conference on Multidisciplinary Approaches. Nugegoda, Sri Lanka: University of Sri Jayewardenepura; 2015. 